to emphasize that the procedures under which building grants are epproved by the University Grants Committee must be devised and applied in close and constant consultation with the universities. This essential consultation would be facilitated, he suggests, if the University Grants Committee were to appoint a Buildings Sub-Committee with membership drawn mainly from the universities. Whatever the arrangements for consultation may be, it is essential that there should be a clear understanding between the members and officers of the University Grants Committee and the universities and their officers at all levels of staffing. If procedures for the control of grant-sided expenditure are to be successful, the present excellent and harmonious relations between the University Grants Committee and the universities must be maintained.

With these concluding words Sir Arthur Rucker endorses, like the Gater Committee, the essential soundness of the present procedures for controlling the expenditure of these large sums of public money, and also, like that Committee, firmly rejects the attack on the system which the Public Accounts Committee maintained for more than a decade. While, however, it is to be hoped that the Public Accounts Committee will not re-open that issue, this further tribute to university administration indicates the outstanding importance of efficient government of universities at the present time, and further, the necessity for securing public under. standing of the work which universities are doing and confidence in the ability with which the universities are meoting the demands made upon them. It is clearly within the terms of reference of the Robbins Committee to inquire into the adequacy of the present pattern of university government if it thought fit ; but on this second issue, it must suffice to observe here that, while the present arrangements for university administration have come so well out of the searching inquiry to which the Gater Committee and Sir Arthur Rucker have subjected them on the finencial side, it is no less important that these arrangements should be adequate to meet the demands which university expansion in Britain is making on them in many other ways.

\section{A UNIFIED TREATMENT OF MODERN OPTICAL THEORY}

\section{Principles of Optics}

Electromagnetic Theory of Propagation, Interference and Diffraction of Light. By Prof. Max Born and Prof. Emil Wolf. With contributions by A. B. Bhatia, P. C. Clemmow, D. Gabor, A. R. Stokes, A. M. Taylor, P. A. Wayman and W. L. Wilcock. Pp. xxvi +803. (London and New York : Pergamon Press, 1959.) 120s. net.

$T$ is quite impossible to do justice to a work of 1 such depth and scope as Principles of Optics within the confines of an ordinary review; even to list the contents would require several pages. A few general remarks will therefore be made in the hope of tempting any reader who has not already done so to look at a copy for himself as soon as possible.

Perhaps the most striking impression that one obtains is of completeness. The scope is best described in the words of the authors' preface : ". . . our discussion is restricted to those optical phenomena which may be treated in terms of Maxwell's phenomenological theory. This includes all situations in which the atomistic structure of matter plays no decisive part. The connection with atomic physics, quantum mechanics and physiology is indicated only by short references wherever necessary." Within this framework it would be difficult to find any aspect of modern optical knowledge that is not covered. But the impression of completeness extends to the treatment as well as to the subject-matter. Compare for a moment the following three brief extracts. On page 111 the equation :

$$
\left(\operatorname{grad} \mathscr{P}_{)^{2}}=n^{2}\right.
$$

is derived, $n$ being the refractive index and $\mathscr{S}_{\text {the }}$ eikonal, followed by the statement "it is the basic equation of geometrical optics". On p. 163 we read "When the (two thin) lenses are in contact equation ... may be written in the form $\mathbf{P}=\mathbf{P}_{1}+\mathbf{P}_{2}$ so that the power of the combination is then simply equal to the sum of the powers of the two lenses". Finally, on p. 249 we read "In a photographic enlarger $\left(\varphi \sim 20^{\circ}\right.$ ), large sources (frosted bulbs or cold-cathode tubes) often provide reasonably efficient illumination. In a cinematograph projector $\left(\varphi \sim 5^{\circ}\right)$ requiring maxium brightness, an electric filament is suitable". It will be seen that the most advanced mathematical treatment, the familiar working formulæ and the practical implications all find a place.

Principles of Optics is valuable as a work of reference; but it may be that its value in showing the interdependence and essential unity of the different approaches may be even greater. Honours students in physics will find here the often-missing links between theoretical and experimental studies. It is interesting to note that even in some of the most mathematical sections the style is clear and vivid. In the early stage of the development from Maxwell's equations we read "Within this laver construct a small near-cylinder bounded by a stockade of normals to $\mathrm{T}$, roofed and floored by small areas $\delta \mathrm{A}, \ldots$. . The diagram is almost unnecessary.

Students should be warned, however, that this is emphatically a book for studying rather than reading. The plan of each section is to begin with the most general theory and proceed later to particular practical cases. A certain amount of searching may therefore be necessary to find some of the more familiar material. For example, the chapter entitled "Foundations of Geometrical Optics" begins with the derivation of the eikonal equation already mentioned and we do not meet Snell's law and the elementary laws of reflexion until seventeen pages later.

There have been so many text-books on optics that it is quite thrilling to find so much that is now in both presentation and material in one volume. Its only disturbing feature is that after spending even a very short time in study one is made to realize the vast depth of the subject and the shallow. ness of one's own understanding of it.

C. A. TAYToR 